\title{
The stone formation in the Memotherm urethral stent implantation area: Is it a rare complication?
}

\author{
Ayhan Karakose, MD; Yusuf Ziya Atesci, MD; Ozgu Aydogdu, MD
}

Izmir University School of Medicine, Department of Urology, Izmir, Turkey

Cite as: Can Urol Assoc J 2014;8(3-4):e213-4. http://dx.doi.org/10.5489/cuaj.1344 Published online March 11, 2014.

\section{Abstract}

Recurrent urethral stricture is one of the biggest problems in urology. Urethral stents as an alternative treatment has been used since 1985. The stone formation in the Memotherm (Angiomed) urethral stent implantation area is a rare complication. We report the case of a 67-year-old man who had a stone in the Memotherm urethral stent implantation area 6 years after his urethral stent surgery.

\section{Introduction}

Recurrent urethral stricture is one of the biggest problems in urology. There are many treatment options for recurrent urethral strictures, including internal urethrotomy, intermittant urethral dilatation and open urethroplasty. These methods, however, may not yield desired results every time. This condition adversely affects quality of life. Urethral stents, as an alternative treatment, have been used since 1985 and many centres have reported successful results. ${ }^{1}$

The stone formation in the Memotherm (Angiomed) urethral stent implantation area is a rare complication. To the best of our knowledge, this is the first study on the diagnosis and management of stone formation in the metal stent Memotherm.

\section{Case report}

A 67-year-old man admitted to the outpatient urology clinic for difficult urination. His medical history revealed previous internal urethrotomy surgery 3 times for the treatment of urethral stricture and the Memotherm urethral stent was placed 6 years before. His physical examination was normal except difficult urination. Routine laboratory investigations revealed normal findings. Kidney, ureter and bladder
(KUB) scan and ultrasound revealed a stone in the urethra. Diagnostic cystoscopy showed a stone in the bulbar urethra (Fig. 1). The stone was endoscopically fragmented with pneumatic lithotriptor at the lithotomy position under spinal anesthesia. The urethral stent was not removed and no Foley catheter was inserted. The operation took 40 minutes. There were no complications during and after surgery. The patient was discharged without any complications on postoperative day 1 . The stent was re-epithelialized on the third month after the stones were fragmented. The urethra was still open postoperatively at the first and tenth year (Fig .2).

\section{Discussion}

Despite the advances in technology, the endoscopic treatment of urethral stenosis does not always yield desired outcomes. The frequent recurrence of stenosis and lack of curative treatment negatively affects a patient's psychology and quality of life. The long-term treatment success rate is $20 \%$ to $45 \%$ after the first internal urethrotomy. The success rate after urethroplasty, using a variety of techniques, is between $90 \%$ and $95 \%$. However, urethroplasty success rates decrease to $40 \%$ in complex urethral strictures. ${ }^{2}$ Alternative methods to treat urethral strictures have been used due to the failure of internal urethrotomy. Therefore, to treat recurrent urethral strictures, permanent metallic urethral stents (UroLume, American Medical Systems; Memotherm, Angiomed) have been used. ${ }^{1-3}$

Memotherm is a thermoactive stent constructed of nitinol. A Memotherm stent expands at body temperature and contracts at colder temperatures, so it is easy to remove and reposition since it does not stick to the tissue. Ponce and colleagues have achieved complete success in 4 patients with complicated urethral stenosis using Memotherm metalic stent with long-term follow-up. ${ }^{3}$

Milroy and colleagues reported a $63 \%$ success rate at long-term follow-up of the permanently implantable UroLume stent in $1993 .{ }^{4}$ Similarly, Sertcelik and colleagues 


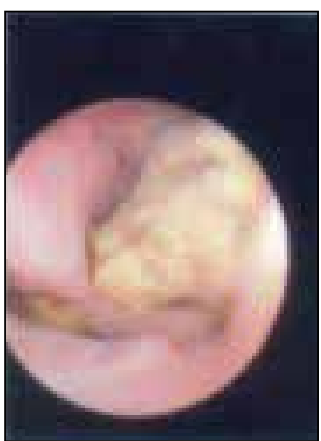

Fig. 1. Diagnostic cystoscopy showing a stone in bulbar urethra.
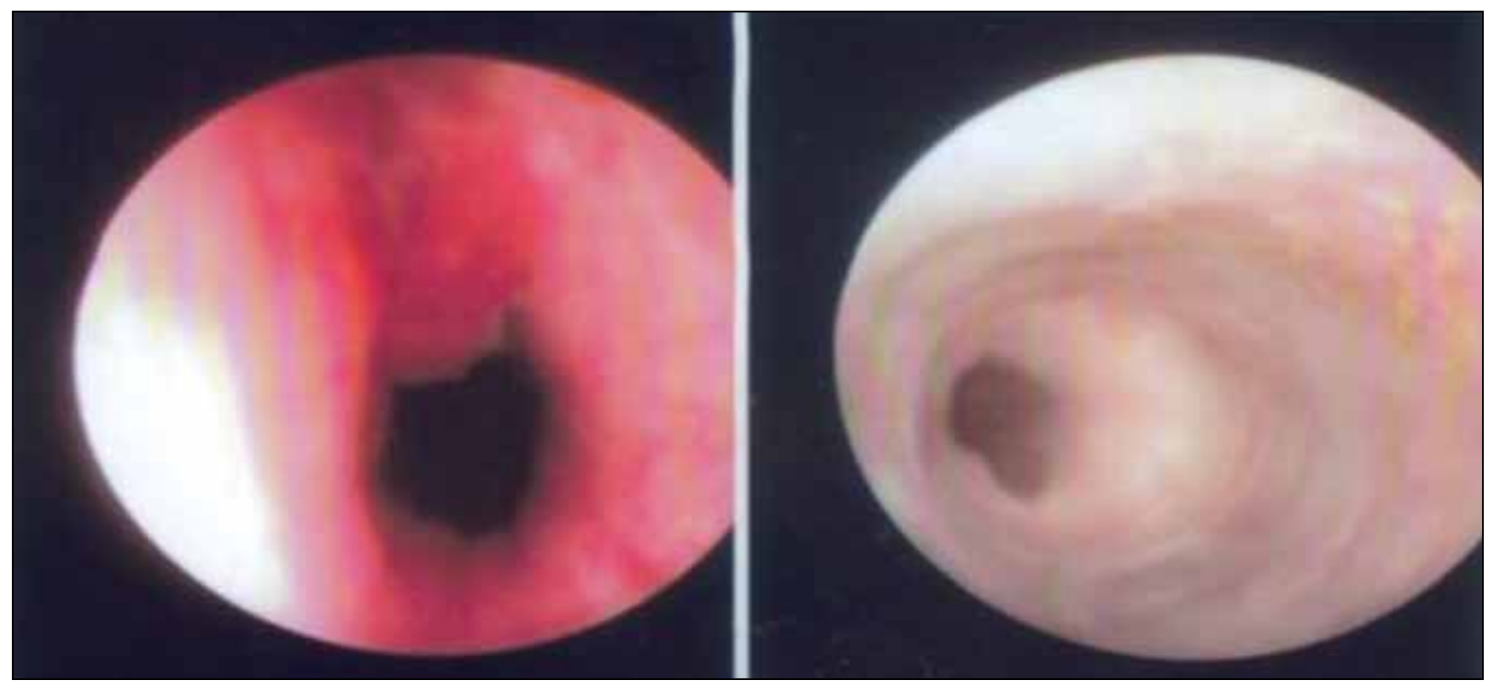

Fig. 2. Appearance of the urethra postoperatively, at the first and tenth year. reported their clinical experience with UroLume in 2000. They found a $87 \%$ success rate at a mean follow-up of 3.8 years in 60 patients with recurrent bulbar urethral stenosis. ${ }^{5}$ Urethral stricture is not the only indication for the use of urethral stents. Urethral stents may be used in patients with infravesical obstruction due to benign prostatic hyperplasia. Previously, we found that the thermo-expandable prostatic stent is an effective minimally invasive treatment of bladderoutflow obstruction, especially in high-risk patients. ${ }^{6}$

In this case, our patient presented with stone formation in the implantation area during follow-up and he was treated with endoscopic stone fragmentation. He did not undergo stent extraction following the endoscopic fragmentation. During the urethroscopy after the endoscopic stone fragmentation at 3 months, 6 months and 1 year, we found sufficient urethral opening and epithelization over the stent. To the best of our knowledge, this is the first study reporting stone formation in the Memotherm urethral stent implantation area.

\section{Conclusion}

Urethral stent implantation is a minimal invasive technique that can be safely and effectively used as a primary surgical procedure to treat recurrent urethral stricture. In the event of stone formation in stent implantation, these stones could be fragmented using endoscopic lithotripsy without needing to remove the stent.
Competing interests: Dr. Karakose, Dr. Atesci and Dr. Aydogdu all declare no competing financial or personal interests.

This paper has been peer-reviewed.

\section{References}

1. Braf $Z$, Chen J, Sofer $M$, et al. Intraprostatic metal stents more than 6 years clinical experience with 110 patients. J Endourol 1996;10:555-8. http://dx.doi.org/10.1089/end.1996.10.555

2. Sertcelik MN, Bozkurt IH, Yalcinkaya F, et al. Long-term results of permanent urethral stent Memotherm implantation in the management of recurrent bulbar urethral stenosis. BJU Int 2011;108:1839-42. http://dx.doi.org/10.1111/j.1464-410X.2011.10230.x

3. Campuzano P, Gonzalez SC, Rodriguez TJ, et al. Treatment of urethral stenosis with thermo-expandable prosthesis (Memotherm): Our experience. Arch Esp Urol 2000;53:253-8.

4. Milroy EJG, Allen A. Long term results of UroLume urethral stent for recurrent urethral strictures. J Urol 1996;155:904-8. http://dx.doi.org/10.1016/S0022-5347(01)66342-0

5. Sertcelik N, Sagnak L, Imamoglu A, et al. The use of self-expanding metallic urethral stents in the treatment of recurrent bulbar urethral strictures: Long-term results. BJU Int 2000;86:686-9. http://dx.doi.org/10.1046/j.1464-410x.2000.00891.x

6. Papatsoris AG, El-Husseiny T, Sawada Y, et al. Treating bladder-outflow obstruction with thermo-expandable prostate metal stents. Exp Rev Med Dev 2009;6:357-63. http://dx.doi.org/10.1586/erd.09.13

Correspondence: Dr. Ayhan Karakose, Izmir University School of Medicine, Department of Urology, Karsiyaka, Izmir, Turkey; e-mail: drayhankarakose@gmail.com 